\title{
11
}

\section{Dynamic settlement, landscape modification, resource utilisation and the value of oral traditions in Palauan archaeology}

\author{
David M. Snyder' ${ }^{1}$ W. Bruce Masse ${ }^{2}$ and James Carucci ${ }^{3}$ \\ 1. Ohio Historic Preservation Office, Columbus, Ohio, USA \\ 2. Environmental Stewardship Group (ENV-ES), Los Alamos National Laboratory, New Mexico, USA \\ 3. James Carucci, Cultural Resources Section, Vandenberg Air Force Base, California, USA
}

\section{Introduction}

In their landmark analysis of Palauan kinship, Force and Force (1972) use the symbolic metaphor of 'Just One House' to capture the integration of kinship in traditional Palauan culture. They realised that then-current general anthropological concepts of kinship were not consistently isomorphic with the evidence from Palau, and additionally that kinship was dynamic, both with respect to the age of individuals as they grew older, and also as a product of outside influences brought on by colonisation and assimilation. They were able to focus on the time dynamic due to the good fortune of being able to conduct research in Palau over two widely separated periods of time (1954-1956 and 1971). Using an analogy with archaeology, Force and Force (1972:vi-vii) described the mosaic historic, social and political patterns as 'cultural stratigraphy', with their goal to excavate the various historical layers in order to expose underlying, earlier, presumably more traditional social patterns.

The research framework used by the Forces is a particularly apt model for our own interest in the historical and archaeological record of Palauan settlement. This paper provides the opportunity for its authors to revisit archaeological research initiated in Palau 30 years ago (e.g. Gumerman et al. 1981; Masse et al. 1984), and also allows us to consider and evaluate conceptual changes in archaeological thinking regarding Palauan settlement that have come about through recent intensive and innovative research programs by various colleagues during the past 15 years. This review also focuses our attention on aspects of the dynamic character of Palauan settlement. 
We use the concept of settlement system in this paper to mean an integrated cultural pattern for the procuring, processing, use and discard of materials. The structure and organisation of the settlement system are integrated with the environment and with the ideational. That is, the environment does not determine the settlement system; rather, the settlement system is a part of the environment. And, at the same time, the settlement system is not uniquely determined by ideas, but cultural patterns, symbols and ideas actively impose on shaping the settlement system.

In all settlement systems, we expect to see responses to environmental variability. We expect to see over-exploitation of certain resources from time to time. Even under similar environmental conditions, we expect there will be different cultural responses that will come out of different settlement systems because of differences in belief and custom. At the same time, we also expect that different cultures will try similar approaches to solving different environmental challenges.

Previous and current models of warfare, climate forcing, population stress, sea-level change, anthropogenic subsistence over-harvesting, and historic contact social and demographic patterns all contribute to a general model for integrated Palauan settlement behaviour. A particular focus is on Palauan oral history, in which we discuss the general nature and reliability of oral traditions by analogy with recent chronometric studies of Hawaiian myth and oral tradition, and then present oral traditions relating to settlement behaviour in the Rock Islands and differences between the Rock Islands and elsewhere in the archipelago. We conclude that landscape and resource diversity led to an inherent dynamic plasticity for settlement in traditional Palau, with potential lessons for sustainability (and the related concepts of resilience and flexibility) in the face of modern economic and climate change.

\section{Physical environment}

The Palau archipelago contains more than 350 islands in a $150 \mathrm{~km}$ long north-to-southwest trending arc in the Caroline Islands of western Micronesia (Figure 1). The islands are part of the Palau ridge crest, one of several arcuate volcanic ridges separating the basin of the Pacific Ocean from that of the Philippine Sea. The approximate centre of equatorial Palau is $7^{\circ} \mathrm{N}$ and $134^{\circ} \mathrm{E}$, about $870 \mathrm{~km}$ east of Mindanao in the Philippines and $900 \mathrm{~km}$ north of Irian Jaya. The following summary is largely extracted from a recent review of Palauan archaeology and physical environment (Masse et al. 2006; see also Mason 1955; US Army 1956; Vessel and Simonson 1958). Not included in this discussion are the isolated southwest islands of Palau, Sonsorol, Tobi, Pulo Ana and Merir, which are more than $280 \mathrm{~km}$ southwest of Angaur, and do not appear to have played a significant role in Palauan settlement-system history for the occupants of the main body of the archipelago between Angaur and Kayangel to the north (Osborne 1966; Intoh 2008).

Palau has a maritime tropical climate with little seasonal variation. The mean annual temperature is around $27^{\circ} \mathrm{C}$, humidity $82 \%$, and annual rainfall averaging around $3800 \mathrm{~mm}$. February through April tends to be slightly drier than the other months. The most notable seasonal climatic difference is in the nature and direction of prevailing surface winds, affecting rainfall, humidity, tides, currents, sea swells and marine life. The winds are largely bimodal; during June to September west or southwest trade winds predominate, while during October through April they reverse and come from the northeast. Strong winds and associated large swells and breakers make fishing difficult and boat travel hazardous, with the eastern side of the larger islands being more protected during westerlies, and the western side being more favourable during north easterlies. Johannes (1981) noted that many reef fish species take advantage of the relative calm during the seasonal change in wind patterns for peak spawning periods.

Palau is located within the boundaries of the Indo-Pacific Warm Pool (Gagan et al. 2004). 


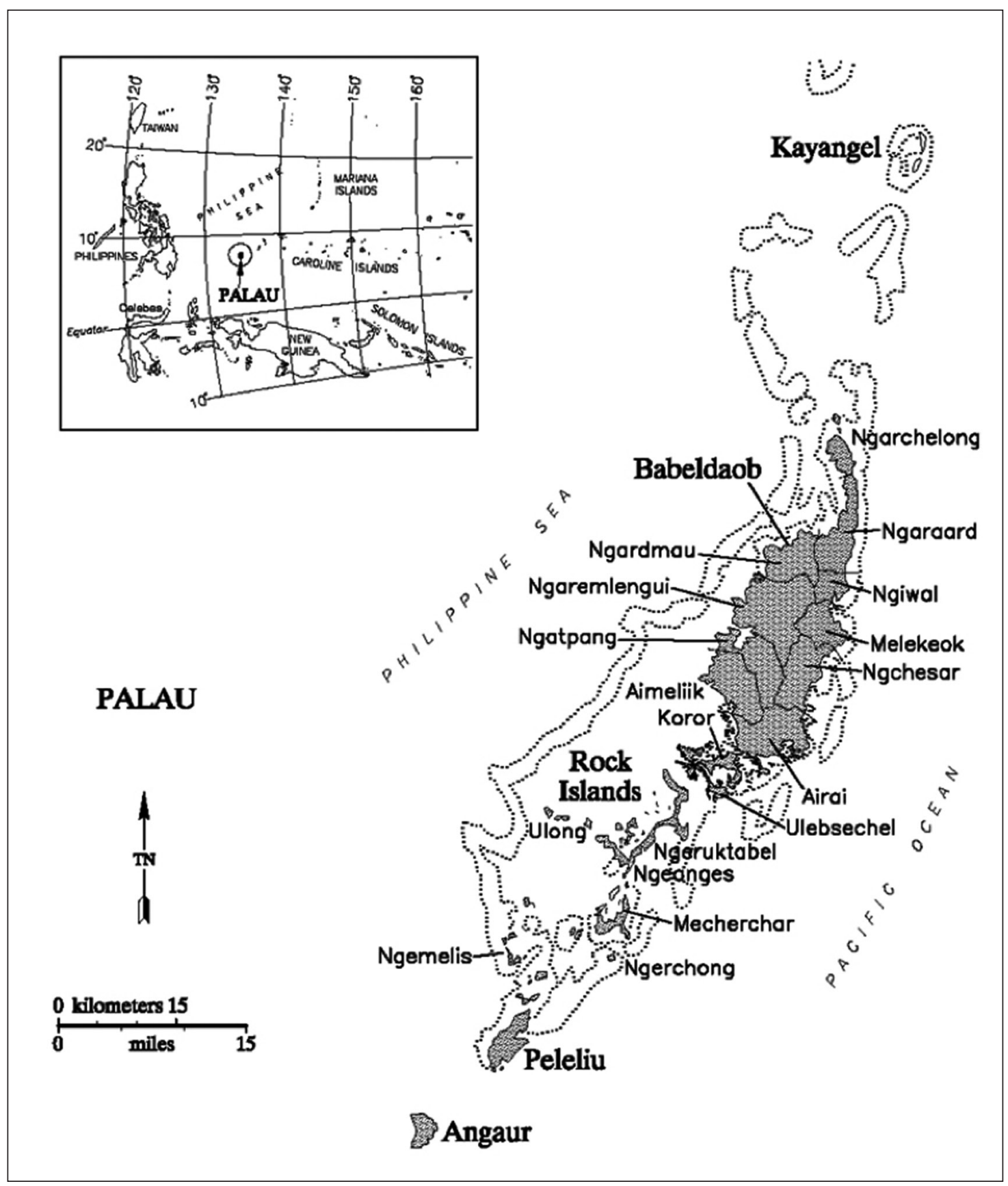

Figure 1. Map of Palau.

This is one of the wettest tropical ocean regions of the world and the largest expanse in the world of water whose annual temperatures exceed $28^{\circ} \mathrm{C}$. As such, Palau is subject to dramatic potential effects from the El Niño-Southern Oscillation (ENSO). Historically, during moderate to strong El Niño events, Palau is in the area experiencing the greatest deficit of annual rainfall, more than $200 \mathrm{~mm}$ (Gagan et al. 2004:Figure 5). While this is a relatively minor percentage of overall rainfall for Palau, rare instances of significant increases in the frequency and severity of El Niño events possibly have had disruptive impacts on Palauan settlement systems (Masse et al. 2006). The fact that Palau is at the southern margin of the western Pacific typhoon corridor indicates that occasional severe cyclones could devastate the archipelago and its reefs, as exemplified elsewhere in western Micronesia (Yamaguchi 1975; Ogg and Koslow 1978). 
Volcanic Babeldaob island, at $333 \mathrm{~km}^{2}$, comprises nearly three-quarters of the land mass of the archipelago and is the second largest island in Micronesia, behind Guam. Five other primarily volcanic islands are also present in the northern portion of the archipelago near Babeldaob, the largest of which is Koror, at less than $9 \mathrm{~km}^{2}$, with Ngerkelau being the smallest, at 0.08 $\mathrm{km}^{2}$. Babeldaob, Koror and Malakal also contain remnants of uplifted karstic limestone reef in addition to the volcanic materials. The maximum elevation above mean sea level in Palau is 242 $\mathrm{m}$ on Babeldaob. Babeldaob's interior uplands are formed by three ridge systems aligned parallel to the island's north-south axis. The eroded and rounded peaks on the volcanic islands are from breccias and interbedded tuffs formed during the Eocene, and create an undulating terrain containing a series of small, narrow and steep-sided valleys. The coastal plains surrounding the uplands are formed by thick clay deposits of weathered andesite, basalt and dacite.

Of the two true atolls at the northern tip of the archipelago, only Kayangel has substantive land mass, at slightly less than $2 \mathrm{~km}^{2}$, with an overall size of about $20 \mathrm{~km}^{2}$, including the barrier reef and lagoon. Kayangel is about $35 \mathrm{~km}$ north of Babeldaob, but only $3 \mathrm{~km}$ north of Babeldaob's barrier reef. The other atoll, Ngaruangel, is about $9 \mathrm{~km}$ northwest of Kayangel, and is approximately one-third the size of Kayangel. The only appreciable land mass within Ngaruangel consists of a barren islet of chunks of reef rock and small patches of sand only about $0.015 \mathrm{~km}^{2}$ in size. Intriguing is the fact that Palauan oral history indicates that a substantial population once thrived on Ngaruangel.

The great majority of the islands in the archipelago are tectonically uplifted coralline limestone islands, referred to locally as Rock Islands, and primarily distributed between Koror and Peleliu. The higher Rock Islands are uplifted ancient reefs dating from the mid Miocene to late Pliocene. The majority are steep, rugged and sinuous karstic islands averaging in elevation between $10 \mathrm{~m}$ and $100 \mathrm{~m}$ above mean sea level, with a maximum elevation of $210 \mathrm{~m}$ on large Ngeruktabel. A series of low coralline islands, including the Ngemelis group, is situated primarily along the southwestern barrier reef. These are formed from less-well-consolidated reef material dating to the Pleistocene and Holocene, and in the case of the Ngemelis group, are slightly uplifted portions of the present living reef system. Although three of the Rock Islands are quite sizeable (Ngeruktabel at greater than $18 \mathrm{~km}^{2}$, Mercherchar at around $8 \mathrm{~km}^{2}$, Ulebsechel at slightly more than $4 \mathrm{~m}^{2}$ ), the remainder are all less than $1.2 \mathrm{~km}^{2}$ in size, typically less than $0.1 \mathrm{~km}^{2}$.

At the southern tip of the archipelago are two sizeable platform-like reef islands, Peleliu at nearly $15 \mathrm{~km}^{2}$ and Angaur at slightly more than $8 \mathrm{~km}^{2}$. Both islands contain high limestone ridges, like the Rock Islands, but also contain extensive areas of low flat uplifted reefs that form broad platforms of land.

Table 1 lists the 22 largest islands in the archipelago, noting area, soil types and shoreline lengths. About $75 \%$ of the soils on the volcanic islands are highly acidic and severely leached latosols, with the remainder consisting of poorly weathered and shallow lithosols, alluvial deposits, bog soils (muck and peat) and unconsolidated calcareous sands (Shioya sand). Babeldaob exhibits the greatest diversity of soils and landforms. The Rock Islands are dominated by limestone outcrops and Shioya sand, while the two platform islands are notable for the presence of bog soils and other soils on limestone. Peleliu is also notable for extensive stands of mangrove forest.

Most of the islands in the archipelago are covered with thick stands of dense mixed tropical forest, with the remainder including savanna (on the volcanic islands), agroforest, or secondary vegetation. Forest vegetation types include upland, swamp, mangrove, plantation, and limestone forests. The upland forests of the volcanic islands are the most species diverse in Micronesia. 
Table 1. Land area, shoreline length and soil types of the largest islands and island groups in the Palau archipelago, from north to south.

\begin{tabular}{|c|c|c|c|c|c|c|c|c|c|}
\hline $\begin{array}{l}\text { Island name and } \\
\text { geological type }\end{array}$ & $\begin{array}{c}\text { Total area } \\
\left(\mathbf{k m}^{2}\right)\end{array}$ & $\begin{array}{c}\text { Shoreline } \\
\text { length } \\
\text { (km) }\end{array}$ & $\begin{array}{c}\text { Mangrove } \\
\text { forest } \\
\left(\mathbf{k m}^{2}\right)\end{array}$ & $\begin{array}{c}\text { Soil on } \\
\text { volcanics } \\
\left(\mathbf{k m}^{2}\right)\end{array}$ & $\begin{array}{l}\text { Alluvial } \\
\text { soils } \\
\left(\mathbf{k m}^{2}\right)\end{array}$ & $\begin{array}{c}\text { Bog soils } \\
\left(\mathrm{km}^{2}\right)\end{array}$ & $\begin{array}{c}\text { Shioya } \\
\text { sand } \\
\left(\mathbf{k m}^{2}\right)\end{array}$ & $\begin{array}{c}\text { Soils on } \\
\text { limestone } \\
\left(\mathbf{k m}^{2}\right)\end{array}$ & $\begin{array}{c}\text { Limestone } \\
\text { outcrop } \\
\left(\mathbf{k m}^{2}\right)\end{array}$ \\
\hline \multicolumn{10}{|l|}{ Atoll } \\
\hline Kayangel atoll & 1.72 & 10.61 & & & & 0.21 & 1.14 & 0.42 & \\
\hline \multicolumn{10}{|l|}{ Volcanic } \\
\hline Ngerechur & 0.31 & 3.06 & & 0.26 & & & 0.05 & & \\
\hline Ngerkelau & 0.08 & 1.29 & & trace & & & 0.08 & & \\
\hline Babeldaob & 366.48 & 157.52 & 33.67 & 313.36 & 11.19 & 5.85 & 1.35 & & 1.06 \\
\hline Koror & 8.89 & 26.55 & 1.55 & 4.56 & 0.08 & 0.03 & & & 2.67 \\
\hline Ngerekebesang & 2.28 & 9.81 & 0.13 & 2.05 & & & & & \\
\hline Malakal & 0.47 & 4.18 & & 0.44 & & & & & 0.03 \\
\hline \multicolumn{10}{|l|}{ Rock Islands } \\
\hline Ngerchol & 0.65 & 8.21 & & & & & & & 0.65 \\
\hline Ulebsechel & 4.33 & 20.60 & & trace & & & 0.03 & & 4.30 \\
\hline Ngeruktabel & 18.62 & 91.55 & & & & & 0.05 & & 18.57 \\
\hline Bungetiou & 1.19 & 10.94 & & & & & & & 1.19 \\
\hline Ulong & 0.59 & 4.67 & & & & & 0.05 & & 0.54 \\
\hline Ngerukuid & 0.47 & 6.92 & & & & & 0.03 & & 0.44 \\
\hline Ngeanges & 0.13 & 1.80 & & & & & 0.06 & & 0.07 \\
\hline Mercherchar & 8.03 & 43.44 & & & & & 0.03 & & 8.00 \\
\hline Ngerchang & 0.44 & 3.22 & trace & & & & 0.34 & 0.10 & trace \\
\hline Babelomekang & 0.21 & 3.38 & & & & & & & 0.21 \\
\hline Ngemelis group & 1.18 & 14.32 & trace & & & & 0.30 & & 0.88 \\
\hline Uchuangelokel & 1.14 & 5.95 & & & & & 0.13 & & 1.01 \\
\hline Ngedebus & 1.04 & 6.28 & & & & & 0.88 & 0.03 & 0.13 \\
\hline \multicolumn{10}{|l|}{ Platform } \\
\hline Peleliu & 14.84 & 39.90 & 2.46 & & & 0.70 & 1.53 & 1.76 & 8.39 \\
\hline Angaur & 8.08 & 13.35 & trace & & & 0.65 & 0.31 & 4.09 & 3.03 \\
\hline
\end{tabular}

Food plants observed at historic European contact in AD 1783 were the dry taro, 'giant swamp' (wetland) taro, coconut palm, breadfruit, tropical apple, Malay apple, banana, greater yam and tropical almond. Other significant plants included turmeric, the betel-nut palm and bamboo. The only economically significant quadruped in the archaeological record is the pig. Quite remarkably and of some consequence for our discussion of Palauan settlement, pigs had been extirpated throughout the archipelago sometime before AD 1783 (Masse et al. 2006), with only cats and ubiquitous rats being present. A variety of birds, the giant fruit bat and land crabs were among the few edible terrestrial fauna that contributed to human subsistence at contact.

A barrier and fringing reef complex surrounds all but Angaur and Kayangel, encompassing more than $1200 \mathrm{~km}^{2}$ of variable lagoon with a maximum depth of about $50 \mathrm{~m}$. A diversity of marine environments reflects an equal diversity of marine species available for human 
exploitation and consumption (Johannes 1981; Masse 1986, 1989; Carucci 1992; Fitzpatrick and Kataoka 2005; Fitzpatrick and Donaldson 2007). Mangrove swamps, estuaries, sandflats, seagrass beds and extensive reef systems occur variously throughout the archipelago, providing a much greater diversity of marine sources than anywhere else in Micronesia. Along with numerous economically important finfish and shellfish species were sea worms, sea cucumbers, sea urchins, starfish, octopus, squid, spiny lobsters, shrimp and crabs. Dugong, hawksbill turtle and green turtle played an important food-distribution social-status role, as did, probably, sharks and whales, based on archaeological evidence. About 80 marine lakes exist in the Rock Islands, connected to the ocean by fissures and solution cavities and responsive to tidal changes. Although these marine lakes are notable for their many unique characteristics and organisms, it is unclear to us what, if any, economic uses these lakes would have had for the occupants of the Rock Islands.

Not all villages and districts would have had equal access to land or marine resources. Clay deposits for making pottery vessels are confined to the volcanic islands. The volcanic islands would have also better supported large-scale horticulture and would have provided more varied plant resources than the limestone islands. Horticulture in the Rock Islands would have been largely limited to soil pockets in limestone pits and sinks and occasional patches of Shioya sand. Shioya sand consists of raised beaches and coastal terraces just above normal wave action, which appear to have developed primarily in the past 3000-4000 years. Coves containing deposits of Shioya sand suitable as canoe landings are present on only some of the Rock Islands. Fresh water is a particularly valuable and varied resource throughout the archipelago. Babeldaob contains perennial streams, a pond and a small lake. The moderate porosity and high permeability of the carbonate soils of the Rock Islands inhibit the development of potable water sources, being limited to a few fresh-water seeps and pockets of Shioya sand suitable for the development of Ghyben-Herzberg fresh-water lenses that can be tapped by shallow wells. Angaur and Peleliu support larger fresh-water lenses, although during periods of drought, even these may become brackish or disappear completely. We suspect that the dense stands of coconut palms on deposits of Shioya sand throughout the limestone islands were deliberately planted, in part to provide a source of nourishing liquid in areas normally lacking potable water and during periods of drought.

\section{Past and current models of Palauan settlement}

Palau has been continuously occupied since ca. 3100-2900 cal. BP (Fitzpatrick 2003; Liston 2005; Clark et al. 2006; Masse et al. 2006), although paleoenvironmental data from Babeldaob is suggestive of human occupation as early as $4300 \mathrm{cal}$. BP (Liston 1999; Athens and Ward 2001). The present data supports a date for initial colonisation at around 3400-3100 BP, as suggested by Clark et al. (2006), but the absence of intensive testing throughout the Rock Islands and portions of the volcanic islands leaves the door open both to push back this date and to provide data for a more comprehensive understanding of early Palauan settlement before $500 \mathrm{BC}$.

At initial sustained European contact in AD 1783 (Parmentier 1981, 1987; Keate 2002; Nero 2002), Palau housed a number of autonomous villages (beluu) that were politically organised into various village districts or federations (renged). Krämer (1919) provides a population estimate of 25,000 for Palau at initial sustained European contact in 1783, while Semper (1982) gives a population estimate of perhaps as many as 40,000-50,000. These values are problematic, but provide a starting point for much-needed population studies for Palau. Fifteen federations (renged) existed in Palau at European contact, corresponding to the 10 
modern states depicted on Babeldaob Island in Figure 1. An 11th federation on Babeldaob, Ngersuul south of Melekeok, has since become extinct. At European contact, two federations were in the process of expansion, Koror and Melekeok, attempting to subjugate other renged. It is clear from historic contact-period observations and from Palauan oral history that the pattern of competing federations extended several hundred years back in time before European contact. Liston and Tuggle (2006) suggest that earlier earthwork village federations (discussed below) may have been roughly equivalent to the anthropological concept of small chiefdoms (e.g. Service 1962; Carneiro 1981:45), although they caution that political centralisation is not always the necessary product of such competition. We think it premature to define levels of early Palauan social complexity without more additional archaeological field study.

Palauan villages at European contact (with their notable absence in the Rock Islands, as discussed below) were nucleated, in contrast to the isolated hamlets and dispersed homesteads of many other Pacific Islands. Residences, club houses and village meeting houses (bai) were constructed on well-built stone platforms around a central paved square, with all being linked by stone pathways (Masse and Snyder 1982; Liston and Tuggle 2006). These platforms, along with burial, resting and cooking platforms, were constructed from multiple layers of basalt stones around an earthen core. Other stone features included docks, boathouses, shrines, wells and bathing places.

Monumental earthwork terrace complexes comprise a prominent class of archaeological features on the volcanic islands. However, as discussed below, they played an earlier role in Palauan settlement-system history, before the stonework villages. Villages did not exist on the Rock Islands at the time of European contact, but there is ample evidence for such earlier stonework villages. At contact, the Rock Islands were subject to what were probably frequent periodic visits to glean marine resources (e.g. Keate 2002:74).

The idea of a settlement system, that at any one time during a particular period the materialculture remains were created and subsequently discarded within an integrated culture, may seem almost taken for granted today. However, the concepts of settlement pattern and settlement system were still in their infancy in 1953-1954 when pioneering Palauan archaeologist Douglas Osborne $(1958,1966)$ first began archaeological survey of Palau.

Osborne, while not being formally trained in settlement-system archaeology, clearly understood that because of the considerable geographic diversity of landscapes within the Palau archipelago, it would be necessary to visit as many of the larger islands and districts as possible. To this end, Osborne visited Kayangel Atoll; he identified 55 stonework villages and earthwork terrace complexes on volcanic Babeldaob Island through both survey and aerial photographic interpretation, and visited most of them; he visited all five of the smaller volcanic islands, identifying another 33 or so villages and earthwork features; he visited and identified 42 sites on Peliliu and Angaur; and he visited several of the larger Rock Islands. Although Osborne's visits generally were quite brief, he recognised that resources were not uniformly scattered throughout the archipelago. For example, the clay for making pottery was restricted to the volcanic islands, and water was a scarce commodity on many of the coralline limestone islands. Osborne likewise soon realised that Palauan elders and some of his guides had oral traditions relating to a significant number of the sites that he visited. To Osborne's credit, he recorded and published lengthy synopses of most or all of these traditions.

Intensive test excavations conducted by Osborne in 1968-1969 at a few locations defined during his initial survey in the archipelago yielded only limited information of value for our interests in Palauan settlement systems (Osborne 1979). In a similar vein, work conducted and preliminarily reported on by Jun Takayama (1979; Takayama and Takasugi 1978) from the 
Rock Island of Ulsbachel yielded only minor insights into the settlement history of the Rock Islands. And investigations by Laurie Lucking (1984) on Babeldaob's earthwork terraces were limited by the inability to employ mechanised equipment (e.g. backhoes and front-end loaders) to study monumental earthworks.

The Southern Illinois University at Carbondale Palau Archaeological Project (SIUPAP) began in 1979 (Gumerman et al. 1981). The settlement model that we developed during the 1980s (e.g. Masse and Snyder 1982; Masse et al. 1984; Masse 1989; Snyder 1989; Snyder and Butler 1997; see Table 2) was derived from settlement and land-use models developed in the American southwest and southeast (e.g. Masse 1991) and was too rigidly applied to Palau. The model centred on the geographical spacing of 'traditional' stonework villages on the volcanic islands (Masse and Snyder 1982; Snyder and Butler 1997), and saw the Rock Islands and the slew of smaller islands in and around the main volcanic islands as special resource-procurement zones. The volcanic island villages were seen as pie-shaped wedges. Beginning with the lagoon, where the wedge was the widest, and continuously narrowing to the higher ground near the centre of the island, the volcanic island village model gave maximum access to vital lagoon and mangrove swamp resources, allowed for village placement on the lower coastal ground where there were soils for a variety of different gardens. Within each pie-shaped wedge there would have been a primary village and several smaller associated villages.

Masse's work in the Rock Islands validated and amplified the assumptions by Osborne regarding the presence of substantial and permanent stonework villages scattered throughout the limestone islands of the central archipelago (Masse et al. 1984; Masse 1989). Despite the absence of volcanic stone building materials and the local peculiarities of the limestone terrain, the Rock Island stonework villages contain a suite of features functionally equivalent to features of volcanic island stonework villages (Figure 2) except that they were constructed from chunks of coralline limestone rather than basalt (Masse 1989; Masse et al. 2006). These Rock Island villages would have been heavily dependent on the resources of the lagoon (Masse 1989; Carucci 1992), although there also would have been important resources on the Rock Islands. Two chronological questions regarding the Rock Island stonework villages are of obvious importance for understanding settlement-system history. When were the stonework villages built and how long were they occupied? Our tentative answer was AD 1200 through 1450.

To accommodate the presence of Rock Island villages we first thought to incorporate ideas of population growth. As the population of Palau grew over a span of somewhat more than two millennia, new villages were added to fill existing space. When SIUPAP radiocarbon dating provided earlier dates for Rock Island stonework-village associations (ca. AD 1200-1450) than for volcanic island stonework-village associations (ca. AD 1500+), we viewed the Rock Islands as filling up earlier, with overflow expanding across the volcanic islands. As population continued to expand, resources were over-exploited. First, in the Rock Islands in the 14th and 15 th centuries $\mathrm{AD}$, and later in the volcanic islands, we see a rapid decrease in the population.

By the time of Krämer's (1919) research at the beginning of the 20th century, the population of Palau had declined to about 4000, not too different from Kubary's (1873) estimate of 3000 people a generation before. Krämer recorded volcanic-island villages that he described as abandoned. This pattern is likely to reflect disease, assimilation and conflict, similar to other populations following initial European contact (Stannard 1989; Reff 1991).

Archaeological research during the past 20 years does not support much of this model of the traditional Palauan settlement system, particularly Masse's (1990) estimated initial colonisation at around $2000 \mathrm{cal}$. BP (see Table 2). Our failure was, in part, due to the age-old archaeological nemesis of sampling - our limited sample of excavated sites and chronometric dates masked the 


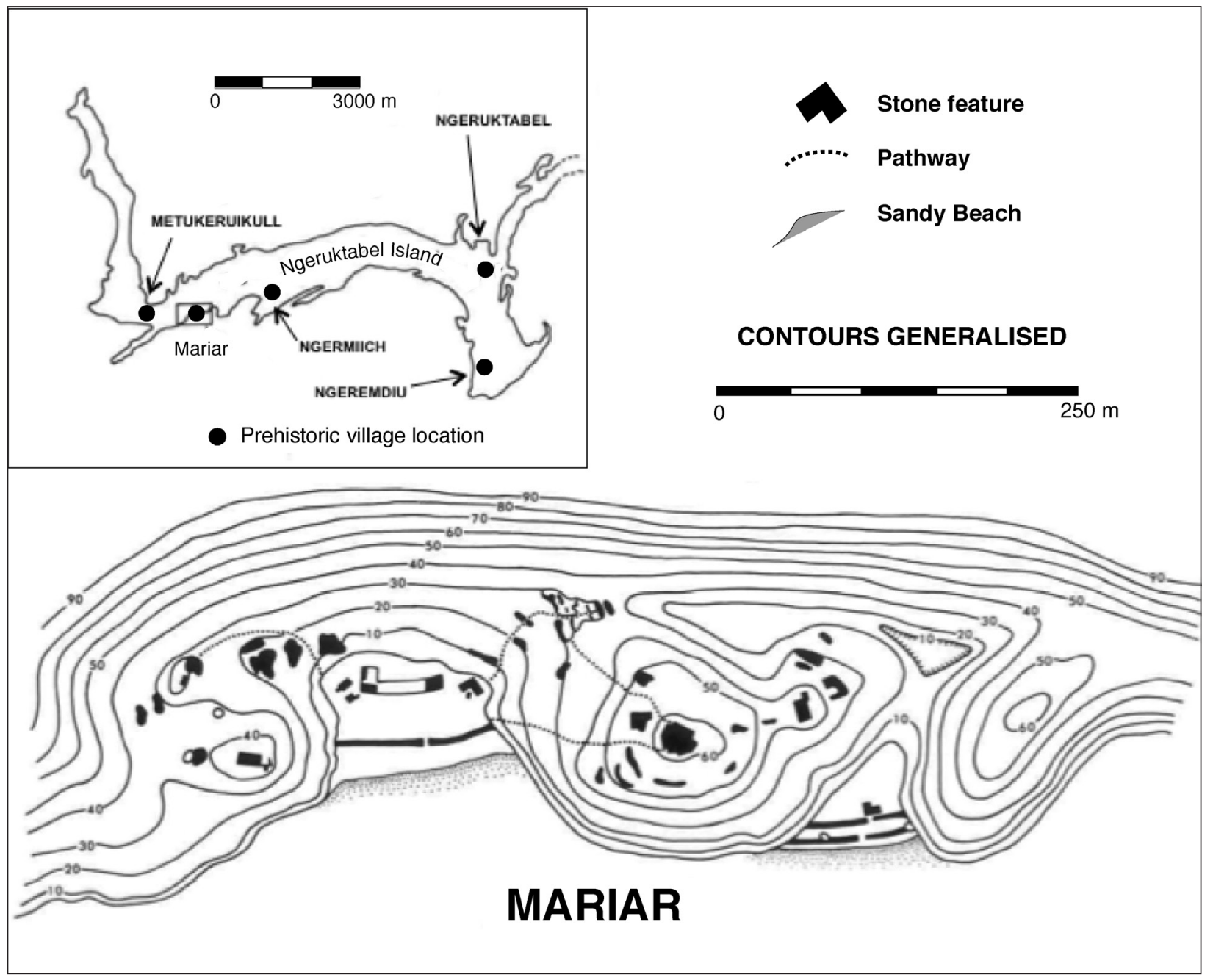

Figure 2. Map of the Rock Island stonework village of Mariar, along with the locations of five stonework villages on the island of Ngeruktabel.

overall complexity and longevity of Palauan settlement, but equally important are differences between our initial and current perceptions of the nature of culture change, a topic we return to at the end of this paper.

Our understanding of Palauan settlement patterns and systems has greatly accelerated due to the 1996-2003 monitoring investigations, survey and data recovery associated with the construction of the $85 \mathrm{~km}$ long road system encircling Babeldaob Island (Wickler et al. 2005). In addition to adding hundreds of radiocarbon dates from well-dated features and site complexes (Liston 2005), the work has given us an exciting new perspective on the monumental earthwork terraces (Liston and Tuggle 2006; Liston 2009).

Jolie Liston and her colleagues (Wickler 2002; Liston and Tuggle 2006; Phear 2008; Liston 2009) have now provided the first detailed overviews of the construction and use history of earthwork complexes in Palau, particularly from the northern Babeldaob districts of Ngiwal and Ngaraard (Table 2). Palauan earthworks are created by both cut-and-fill and sculpting of ridges and hilltops. The dominant features are step terraces of great variety, which occur with or in occasional isolation from high points termed 'crowns' and ditches. Together, these features cover at least $20 \%$ of the total landmass of Babeldaob. More than 100 crowns are present throughout the Babeldaob earthworks. They have nearly vertical sides and rise 3-10 m above the 
Table 2. A comparison of Palauan archaeological periods and phases with respect to the 1980s Southern Illinois University Palau Archaeological Project (SIUPAP) model with the current 'Liston' model developed from data collected by International Archaeological Research Institute, Inc. Also depicted are major climatic phases and events.

\begin{tabular}{|c|c|c|c|}
\hline Date & Siupap model (e.g. Masse 1989) & Liston model (e.g. Liston 2009) & Climatic events (e.g. Nunn 2007) \\
\hline AD 1800 & TRADITIONAL-historic & & \\
\hline 1700 & TRADITIONAL-initial contact & & \\
\hline 1600 & TRADITIONAL-protohistoric & & MAUNDER MINIMUM \\
\hline 1500 & TRANSITIONAL & & \\
\hline 1400 & ROCK ISLAND VILLAGE & & \\
\hline 1300 & & STONEWORK ERA & AD 1300 EVENT \\
\hline 1200 & ROCK ISLAND VILLAGE & & LITTLE ICE AGE BEGINS \\
\hline \multicolumn{4}{|l|}{1100} \\
\hline \multicolumn{4}{|l|}{1000} \\
\hline 900 & late & & \\
\hline 800 & & TRANSITIONAL ERA & \\
\hline 700 & early & & \\
\hline 600 & RESOURCE INTENSIFICATION & & MEDIEVAL WARM PERIOD \\
\hline 500 & COLONISATION & late & AD 536 EVENT \\
\hline \multicolumn{4}{|l|}{400} \\
\hline \multicolumn{4}{|l|}{300} \\
\hline \multicolumn{4}{|l|}{200} \\
\hline \multicolumn{4}{|l|}{100} \\
\hline$A D$ 1/1 BC & COLONISATION & & \\
\hline \multicolumn{4}{|l|}{$100 \mathrm{BC}$} \\
\hline 200 & & middle & \\
\hline \multicolumn{4}{|l|}{300} \\
\hline 400 & & early & \\
\hline 500 & & EARTHWORK ERA & \\
\hline \multicolumn{4}{|l|}{600} \\
\hline \multicolumn{4}{|l|}{700} \\
\hline \multicolumn{4}{|l|}{800} \\
\hline \multicolumn{4}{|l|}{900} \\
\hline \multicolumn{4}{|l|}{1000} \\
\hline \multicolumn{4}{|l|}{1100} \\
\hline \multicolumn{4}{|l|}{1200} \\
\hline \multicolumn{4}{|l|}{1300} \\
\hline 1400 & & SETTLEMENT AND EXPANSION ERA & \\
\hline \multicolumn{4}{|c|}{ [LATE COLONISATION] } \\
\hline \multicolumn{4}{|l|}{1600} \\
\hline \multicolumn{4}{|l|}{1700} \\
\hline \multicolumn{4}{|l|}{1800} \\
\hline \multicolumn{4}{|l|}{1900} \\
\hline \multicolumn{4}{|l|}{2000} \\
\hline \multicolumn{4}{|l|}{2100} \\
\hline \multicolumn{4}{|l|}{2200} \\
\hline \multicolumn{4}{|l|}{2300} \\
\hline 2400 BC & & [EARLY COLONISATION] & \\
\hline
\end{tabular}


surrounding landscape. Nearly all crowns have an associated ring ditch up to $5 \mathrm{~m}$ deep, with the few excavated examples also containing palisades; additional ditches are present on ridgelines and between crowns.

Earthwork villages are located on low hillsides or along narrow ridgelines inland and upland from historic stonework settlements. They are characterised by earth platforms containing evidence for wooden structures, occasional stone features (e.g. pathways and facings for the earth platforms), and dense midden deposits. At least four, and perhaps as many as seven, such villages have been identified in association with the Ngaraard earthwork terraces. The initial construction of earthwork terrace complexes began as early as $500 \mathrm{BC}$, with the most intense period of terrace/village construction and use being between about $150 \mathrm{BC}$ and $\mathrm{AD}$ 500. Terrace construction thereafter significantly declines until about AD 800, after which the earthwork terraces cease being focal points of activity. By around AD 1000-1200, the transition to coastal stonework villages on Babeldaob begins.

Liston and Tuggle (2006) suggest that the earthwork terrace complexes served as small fortified polities in which villages were defensively protected by the crown and ditch/palisade features noted above. The crowns served as fortified outposts, lookouts and brief refuges, and were visible symbols of power. What is still very unclear is the degree to which, if at all, some of the step terraces may have served as dryland agricultural field plots or for arboriculture. If the step terraces did not have a horticultural/arboriculture function, this raises a critical question as to where such activities took place on the landscape.

In addition to the recent work on the volcanic-island earthwork terraces, great strides have been made in the identification of early pre-earthwork terrace habitation sites on Ulong along the western barrier reef by Geoffrey Clark and his colleagues (e.g. Clark 2005; Clark, et al. 2006) and at Chelchol Ra Orrak near Babeldaob by Scott Fitzpatrick (2003). Burials and midden deposits have been found dating back to 3100-2900 cal. BP, with a reasonable assumption of colonisation in Palau at least by 3400 cal. BP.

As part of the dating of their excavated midden materials, Clark and his colleagues (2005; Clark et al. 2006) were able to obtain food shell collected and eaten in AD 1783 by the shipwrecked survivors of the British East India packet Antelope which had run aground on a reef adjacent to Ulong. This permitted them to obtain data for local reservoir correction $(\Delta R)$ for use with the radiocarbon dating of marine shell. While not absolutely convincing, they built a reasonable argument for $\Delta R=0$ for at least some marine-shell species, rather than the $\Delta R=-$ 250 year recently proposed by Masse and his colleagues (Masse et al. 2006). While the primary intention of Clark and his colleagues was to be able to generate a more accurate date for their model of Palau colonisation, this also calls into question the presumed dating of stonework villages at around AD 1200-1450/1500 in the Rock Islands (e.g. Mariar on Ngeruktabel island, Ngeanges and the Ngemelis group), previously excavated as part of the SIUPAP effort (Masse et al. 1984; Masse 1989; Masse et al. 2006). Using the suggested $\Delta \mathrm{R}=0$, the Rock Island stonework villages would date at around AD 1450-1750 (as depicted in Masse et al. 2006:Figure 7). Oral traditions collected during the SIUPAP fieldwork in 1981 and discussed below provide support for the revised AD 1450-1750 dating for most or all of the Rock Island stonework villages.

This dating also affects interpretation of the potential effects of the Little Ice Age (ca. AD 1300-1800) on stonework villages in the Rock Islands (Masse et al. 2006), and plays an important role in understanding Palauan settlement behaviour during the Little Ice Age (Table 2). We originally believed that the beginnings of the Little Ice Age and Patrick Nunn's (2000, 2007) related so-called 'AD 1300 Event' (a pan-Pacific environmental catastrophe) was a catalyst leading to the over-harvesting of inshore marine resources during the occupation of 
the Rock Island stonework villages (Masse 1989; Carucci 1992; Masse et al. 2006). It now appears that this apparent period of over-harvesting would have taken place about the time of the Maunder Minimum (ca. AD 1645-1715), which was the coldest portion of the Little Ice Age. While more data are needed, it is now not unreasonable to hypothesise that the Maunder Minimum had a direct role in the proposed over-harvesting of inshore marine resources, the extirpation of pig in Palau (Intoh 1986; Masse et al. 2006), and the apparent instability in Rock Island stonework-village settlement noted below in oral traditions, which led to the apparent abandonment of the last occupied Rock Island stonework settlements shortly before the wreck of the Antelope in $\mathrm{AD} 1783$.

The traditional Palauan settlement system was likely to have been much more resilient than in our early SIUPAP program thinking. This is particularly evident in the calamitous, nearly catastrophic, social collapse precipitated by forced and heavy-handed colonial administrations during the 19th and early 20th centuries. We see changes occurring in Palau over millennia. Some of these changes required resource balancing necessary for sustainability, while other changes led to permanent, irreversible cultural change. The more that we learn about the dynamics of traditional Palauan culture, the better our understanding will be of the environmental conditions needed for sustainability and the cultural changes that occur when environmental variability exceeds the limits of human systems.

\section{The nature and value of oral tradition, myths and legends}

We when first began research in Palau 30 years ago, we had a nebulous understanding of Palauan oral traditions, and of the value of oral traditions to archaeological research, ranging from very sceptical (Masse) to sympathetic (Snyder). Like most American archaeologists at that time, we were schooled in the four-field approach to anthropology, combining cultural/ social anthropology, linguistics and physical anthropology, along with our archaeological specialisations. However, as material-culture-oriented archaeologists, we had been trained to treat oral traditions with reserved scepticism beyond the passage of a few generations. The general view was that as historical information passed through the filter of oral transmission, each succeeding generation added both to the propensity to distort the information and the cultural introspection of beliefs, values, customs, traditions and history, so that after a handful of generations (100-150 years) the information could no longer be trusted.

We had likewise been taught that myths, i.e. tales of culture heroes and demigods imbued with supernatural powers and existing in a remote time before the present age, were primarily of psychological importance and overwhelmed historical content, despite being viewed as true by the cultures in which they are told. A similar scholarly contempt existed for legends, such as comprise many of the traditional stories in Palau. Legends are typically viewed as 'semihistorical' stories (of unknown or dubious meaningful historical content) that serve to establish local customs, recount the migrations of people, and account for the deeds of heroes. Legends typically combine realism with supernatural and mythic elements. In the discussion that follows, the terms myth and legend are largely viewed as synonymous.

Our Palau fieldwork experiences challenged these preset notions about oral tradition and myth/legend. We rapidly became aware that despite a lack of formal scientific training, Palauans are gifted observers of the natural environment. For example, the observations of Palauan master fishermen are of such detail and quality that they have been proven to aid marine biologists in documenting and understanding many previously unknown aspects of the biology and behaviour of fishes and other marine species (e.g. Johannes 1981; Masse 1985, 1989; McPherson et al. 
2010). Such observational powers were not confined to fishermen, but also included both men and women who had spent their lives gleaning resources from Palau's forests and reefs.

Even more remarkable to us was the richness and detail preserved in oral traditions regarding specific villages in the volcanic islands and the Rock Islands (e.g. Osborne 1966:401404, 424-425). For example, in 1981 we were privileged to interview noted historian Joseph Tellei, Oukerdeu of the Idid clan in Koror and a former police chief in the Japanese colonial administration, regarding his knowledge of villages and chiefly confederations in the Rock Islands. While intrigued by these stories, we nevertheless continued to view such information with caution:

The stories ... recorded from Tellei are sketchy because of ... lack of time to pursue further details (both from Tellei and other informants) and because of the several hundred years of retelling these stories which had undoubtedly altered the original details. Nevertheless, these stories do provide an interesting perspective on this period of Belauan prehistory, and seem to indicate that Belauan social organisation during the rock island village period was perhaps as complex as that observed at historic contact. At the very least, these stories, when combined with the archaeological record, indicate that during A.D. $1200-1450$ the rock islands witnessed a degree of intensive utilization not seen before or afterwards (Masse 1989:76).

Similar scepticism was expressed by Osborne (1966:300) about the story regarding the sizable population once said to be on Ngeruangel atoll, its ability to conquer neighbouring polities, and the subsequent complete destruction of the atoll by a cyclonic storm. Osborne was convinced the story was a fabrication.

Such scepticism regarding the worth of oral tradition and the nature of the myths and legends has been more recently challenged due to a chance encounter by one of the authors with the myths and oral traditions surrounding the eruption of a Hawaiian volcano (Holcomb 1987; Masse et al. 1991; see also Swanson 2008). Because Hawaiian mythology and oral tradition are directly tied into royal chiefly genealogies (i.e. specific myth storylines are stated to have taken place during the reigns of named genealogical chiefs), and because some historically recorded or reconstructible spectacular natural events (e.g. volcanic eruptions, total solar eclipses, the passage of unique long-visible comets) are demonstrably captured and preserved in myth storylines, it is possible to achieve a chronological perspective on the pervasive multifaceted role of myth and oral tradition in traditional Hawaiian culture (Masse 1995, 2010; Masse et al. n.d.). These data suggest there is a powerful historical core to at least some myths and legends that can be objectively retrieved and studied (Masse et al. 2007; Piccardi and Masse 2007; Cashman and Giordano 2008).

At the very least, Hawai' $i$ well illustrates the basic conservative nature of traditional oral myth transmission (Vansina 1985; Rubin 1995; Masse et al. n.d.). Gifted narrators were sought out or occupied inherited positions, and were continuously trained. Myth transmission itself was performance driven (song, dance, chant and appropriate imagery), serving to reinforce the storyline, as did the use of repetition. Myths typically were the property of chiefs/priests and were publicly performed on an annual or more frequent basis, such as during annual solstice ceremonies, the births of royal chiefs and ceremonies surrounding the periodic visits of royal chiefs travelling among islands in the Hawaiian chain. Myth also served to link chiefs with the supernatural powers of mana (supernatural forces believed to dwell in certain persons and sacred objects) as manifested in remarkable natural events. Not only can it be demonstrated that some of the myth storylines match historic natural events, but also that the observational details being 
preserved in the myths often add new scientific or scholarly information to the original historic records. That such detail can be preserved and transmitted within the context of myth storylines across dozens of generations is strong testimony to the potential accuracy and effectiveness of oral transmission.

It would be unwise, though, to entirely dismiss scepticism when dealing with myths and oral traditions. There are many documented processes that serve to garble or destroy the original historic content of myth (Barber and Barber 2004). And there are many other complexly layered structural, cognitive and symbolic aspects to myth. The power of myth, in part, derives from the creation and manipulation of evocative symbols within and between cultural groups. The challenge for archaeology and any historical approach to myth and oral tradition is to meaningfully separate the elements of history and chronology from the diverse structural, symbolic and social aspects of myths.

\section{Rock Island oral traditions}

It is not our purpose here to directly apply this Hawaiian-derived natural-science approach to Palauan oral traditions, nor to demonstrate that an absolute chronology can be derived for Palauan oral tradition, as is the case for Hawai' $i$. There seemingly are significant differences between how myth/legend and oral tradition are used in Palau versus Hawai $i$. The Hawaiian examples serve primarily to emphasise the general value of oral tradition and to suggest that previously collected Palauan traditions have the potential to be mined for additional information regarding Palauan culture history, including settlement, and also that the continued collecting of oral traditions should be an important endeavour.

A number of researchers have commented on the general value of Palauan oral traditions relating to the Stonework Village Era on the volcanic islands reaching back several centuries before European contact (e.g. Kubary 1873; Krämer 1919; Osborne 1966; Parmentier 1981, 1987; Nero 1987, 2002; Masse 1989; Snyder 1989; Lucking and Parmentier 1990; Snyder and Butler 1997; Wickler 2002; Liston 2009). Our aim is to briefly discuss Rock Island oral traditions as they relate to issues of settlement and with relations between the Rock Islands and the volcanic and platform islands of the archipelago. These oral traditions suggest that previously published (e.g. Masse 1989; Masse et al. 2006) assessments of the nature and dating of Rock Island stonework villages require modest revision.

As previously noted, during the 1981 SIUPAP excavations in the Ngemelis group, we (Masse) had the opportunity to discuss Rock Islands oral traditions with Joseph Tellei, with the assistance of then Historic Preservation Office historian Moses Mekoll, with Walter R. Metes as translator (Masse does not speak Palauan). Tellei was then a vigorous 80 years old, and held the chiefly title of Oukerdeu in the highest ranked clan (Idid clan) of Koror. Tellei indicated that he had heard the stories (presumably as a teenager or young man) from Koror and Babeldaob's high chiefs Ibedul Louch (who died in 1917) and IbedulTem (who became Ibedul in 1926). The brief notes (Masse 1981) from Tellei regarding the Ngemelis group and other Rock Islands are presented below.

Around AD 1700 [... a date that Tellei took time to confirm with an original copy of Kubary 1873 that he had in a trunk] Ngeruangel atoll was destroyed by a storm. At that time no one was living on the Ngemelis group. Some of the Ngeruangel survivors, the Ngerbuuch clan, fled to Ngemelis, later moving to Angaur. Their house/stone platform name is Ngerburech. The modern Aimeliik clan and house/stone platform Selau also originally came from Ngeruangel. 
Tellei knew of two stories about what happened to these particular residents of Ngemelis. The first was that they were attacked (or assisted in warfare) by Terebkul, a warrior from Peleliu. The second is that starvation forced them to leave Ngemelis for Babeldaob. Both of these events took place before the time of Captain Wilson, that is before AD 1783 when the British East India packet Antelope was shipwrecked on nearby Ulong Island (see Keate 2002; Clark 2005). Uchelmelis was the chief of Ngemelis at the time of Terebkul's attack, and he lived at Rois village (on Uchularois Island). Uchelmelis eventually moved to Aimeliik, where one of the chiefly titles (but not that of the high chief) is now Uchelmelis.

A famous Palauan love story is that Uchelmelis had a daughter who was courted by Terebkul, when Terebkul was living at Ngerengchol (next to volcanic Malakal Island). One evening they were on the western shore of Ngemelis Island at full moon when the daughter of Uchelmelis lost her grass skirt. Fifteen days later, the turtle that stole her skirt brought it back to the shore (an act that describes the egg-laying cycle of turtles).

Also bearing on this discussion are fuller versions of the Terebkul story published by Osborne (1966:401-404) and Parmentier (1987:288-289) regarding the abandonment of Ulong Island. Apparently Ulong chief Osilek was in control of several Rock Island groups and villages including Ngemelis. Food, artefacts and weapons were constantly being taken from the subject populations to the benefit of Ulong. Finally, the chief of Ngemelis, Uchelmelis, asked Terekbul, a powerful warrior from Peleliu and lover of the daughter of Uchelmelis, to come to the aid of Ngemelis. Uchelmelis and Terebkul painted their normally red war canoes white, and planned to attack Ulong at sunset when their canoes would be hidden by the sunlight behind them. The attack was successful and the population of Ulong fled to volcanic Ngerekebesang, where Osilek had forged a recent alliance with Ngerekebesang chief Uchelkebesadel. Other Ulong groups split up, some going to the Babeldaob village of Ngeburech near Melekeok, and others to Ngeremlengui. After a number of years, the Ngeremlengui refugees from Ulong decided to join those of Ngeburech. Because they did not have a sufficiently large money bead to repay their Ngeremlengui hosts for their past hospitality, they made payment by repaving the stone paths and platforms of Imiong village prior to leaving for Ngeburech.

Ulong was never again reoccupied before the Antelope shipwreck, and a number of years after its defeat by Terekbul and Uchelmelis, the people of Ngemelis moved to Babeldaob. Tellei noted that shortly after this migration, another group of survivors from the Ngeruangel storm may have moved into recently abandoned Ngemelis. These refugees had been living temporarily in Ngerchemai village in eastern Koror. They arrived in Ngemelis and several other Rock Islands at the time Ibedul Kereel was the high chief of Koror, some time before Ibedul Esuch, who ruled Koror at the time of the AD 1783 Antelope shipwreck. The final abandonment of Ngemelis appears to have taken place shortly after Koror made war with some of the villages on Ngeruktabel (discussed below).

Tellei also noted that at the time of the final abandonment of Ngemelis, a boatload of refugees on the way to Koror had to stop at an unnamed location because a woman was pregnant and needed to deliver a baby. The baby girl was named Tmanges because the journey was 'moving up' to the north. Another canoe with refugees passed by the stopped canoe, and invited everyone to come with them to Koror. At this time another woman became pregnant. When they reached Ngerchemai (earlier called Ngeding) in Koror the second pregnant woman delivered a baby who was called Leudii, because the trip was finishing or ending. Leudii became Ibedul Esuch's second wife, and the mother of Lebuu. Lebuu is, of course, 'Prince Lee Boo' of Antelope shipwreck fame (Keate 2002; Nero 2002:Plates 5 and 6) who travelled to England with Captain Wilson. Ibedul Esuch is Wilson's 'Abba Thule' (Keate 2002:Plate 18), and Leudii 
is Wilson's 'Ludee' (Nero 2002:Plate 7), all three being sketched in AD 1783 by Arthur William Devis, a passenger on the shipwrecked Antelope.

Curiously, Captain John McCluer in AD 1791 during a return voyage to Palau indicated that Lebuu was the adopted son of Ibedul (Keate 2002:294-295). Other traditions have suggested that Ludee was Yapese (Keate 2002:389, no. 15). These traditions do not necessarily conflict with Tellei's observation that Leudii (or at least her mother) was from Ngemelis. Perhaps Lebuu's father (if not Ibedul Esuch) was Yapese. At the very least, the Leudii and Lebuu oral traditions provide a robust date for the final abandonment of Ngemelis. If we assume that Lebuu was approximately 16-18 years old at the time of the Antelope shipwreck, as suggested by his sketched appearances, then Ngemelis was abandoned around AD 1765.

Tellei also provided descriptions of two other sets of Rock Island polities, one concerning villages on the largest Rock Island of Ngeruktabel, and the other centered on and near the second largest Rock Island of Mercherchar. There were five widely spaced isolated villages on Ngeruktabel, including Mariar, Ngermiich, Metukeruikull, Ngeremdiu and namesake Ngeruktabel (Figure 2). Mariar was occupied at the same time as Ngemelis [presumably after the Ngeruangel storm], but there were also earlier village occupations at Mariar, Metukeruikull, and Ulong prior to the establishment of a village at Ngemelis.

The village of Ngeruktabel controlled Mariar just prior to a war in which Koror conquered Ngeruktabel. The war with Koror was caused by people from Ngeruktabel who went on a fishing expedition to Ngerengchol (Lee Marvin Beach on Ulebsechel Island). While there, they captured and killed Ibedul Kereel, putting his right hand with his dugong bracelet in a basket that was sent to the chiefs of Koror. The chiefs of Koror got together and discussed a plan for retaliation. The Klotraol (the chief of the fifth clan in charge of security during times of warfare) of Koror married a Ngeruktabel woman and went to live at Ngeruktabel for three months, carefully learning the layout of trails and passes. During a feast in which all the people of Ngeruktabel got drunk, possibly from drinking fermented coconut milk, Klotraol led warriors from Koror into Ngeruktabel and slaughtered all of its inhabitants. Immediately before the raid, the Koror chiefs had spread the word to Mariar and Metukruikull to temporarily leave the island so that they wouldn't get caught up in the war (Ngeremdiu and Ngermiich were already long abandoned by this time). The Mariar and Metukeruikull people decided to move out of the Rock Islands entirely, temporarily residing in Ngermid on Koror island. Chief Ngirachitei (from Metukeruikull/Mariar) talked to Chief Tuchermel of Ngerusar on Babeldaob about settling at Oikull. The Rock Island people had discovered that the food was better at Ngermid and the volcanic islands, so they decided to move permanently to Oikull. Chiefs and bai names at Oikull are all from the Rock Islands (for example, the present [1981] No. 1 chief at Oikull is named Ngirachitei).

When the people from Ngeremdiu abandoned Ngeruktabel Island before Koror's war with Ngeruktabel village, some went to live in Melekeok on Babeldaob. Some of the Ngermiich village people went to Ngerekebesang in Koror, where there is still a piece of land today [1981] called Ngermiich. Others from Ngermiich went to Oliuch (near Melekeok). The Ngeremdiu people in Melekeok began to fight with the Ngermiich people in Oliuch. The Oliuch people were forced to move to Ngerbekuu in Ngiwal. Ngerbekuu proved to be too far from the seashore and subsequently the people moved to more coastal Ngardmau. Ngardmau then started fighting with Koror and Ngeremlengui. The chief of Ngardmau felt that they needed more help in their wars and gave money to high chief Reklai of Melekeok. There were several wars between Ngardmau and Koror, until Ibedul sent bribe money to Reklai to end Melekeok's assistance to Ngardmau. 
Tellei also indicated that Chief Osilek of Ulong was married to a Mariar woman (appropriately named Mariar). A Ngeanges chief was also married to a Mariar woman, but Tellei was unfamiliar with their stories. Ngeanges village was under the control of Metukeruikull. The No. 2 chief Aderdei of Metukeruikull lived on Ngeanges island, which served as a border for Metukeruikull.

Tellei provided a brief sketch for the Mecherchar and Ngerchong (Ngerchang) polity. High chief Iyechaderchemai lived in the principal village on Mecherchar (unnamed). No. 2 chief Obechad lived on Ngerchong, and also ruled the Ngerukuid and Ngemelis groups. Chief Uchercheuar (presumably ranked No. 3) lived at and controlled the Metukercheaus area of southern Mecherchar. Chief Eriu (presumably ranked No. 4) lived on Ngerchong and ruled the half of the island opposite from Obechad, along with the Babelomekang group. Because Ngemelis here is part of a different polity than that in the previously described stories of Uchelmelis and Terukbul, it is suggestive that this polity was active before 'uninhabited' Ngemelis was settled by the refugees from Ngeruangel atoll (thus sometime before ca. AD 1700).

\section{Rethinking culture change and dynamic models of sustainable Palauan settlement}

Palau has been continuously occupied for at least 3000 and perhaps more than 4000 years. During this time, impressive earthwork-terrace complexes come and go; stonework villages come and go, or at least go from the Rock Islands. We have stories of incessant warfare, periods of starvation and major cyclonic storms, such as that which apparently devastated Ngeruangel atoll. And we know of major rapid climatic shifts and events, such as the Little Ice Age with its Maunder Minimum, the so-called 'AD 1300 event', and perhaps related over-harvesting of marine resources in the Rock Islands; and the AD 536 climatic downturn and possibly related increases in El Niño activity. There are many other instances of environmental and cultural change in the Palauan archaeological record.

As with the often polarised debate on current global warming and its effects and causes, it is tempting for archaeologists to paint a very dark picture of environmental/cultural change and to emphasise the negative aspects of change. This is not to imply that global warming and other hallmarks of environmental change are not serious and worthy of debate. Rather, we are concerned with how one approaches the dialogue. For every set of changes, either environmental or social, there are choices and opportunities. Often it is language and perception that prevents us from more clearly seeing the relationship between cause and effect.

Just as memory and the rules of performance play an important role in the faithful transmission of oral traditions, memory and cultural rules hidden from the archaeologist can play a vital role in buffering the effects of environmental and social change. For example, from the snapshot picture that we have from descriptions in the late 19th and early 20th centuries, it appears that many of the villages in the Rock Islands were abandoned (e.g. Krämer 1919; Liston 2009). We suggest that the English word 'abandoned' is not correct or accurate. The villages that did not have occupied houses probably should not be considered abandoned, in the sense that this was island space available for resettlement by clan members or through appropriate channels of exchange. Following the kinship model put forward by Force and Force (1972), perhaps not all, but certainly most, of these villages could be more constructively interpreted as idle or dormant social space. Temporarily, there were no occupied houses, and for the most part no actively tended gardens, but over a span of several generations, it is likely these villages would again have become places of settlement, with tended gardens. In anthropological parlance, at 
least into the mid-19th century, the usufruct rights were clearly established and maintained in the Palauan kinship system.

From an archaeological perspective, as part of a settlement pattern, these idled villages provided flexibility and sustainability. They allowed people to shift from areas where soils and lagoon resources were becoming depleted or over-exploited to areas that been allowed to regenerate during an extended, and culturally sanctioned, period of dormancy.

Even in the mid-to-late 20th century, we find ethnographic and archaeological evidence supporting an interpretation of idled villages rather than abandoned villages. At Ngatpang Village in the early 1950s, Douglas Osborne interviewed an elderly woman (Osborne 1966:Figure 3) about pottery making in the only occupied residence in this village. In the early 1980s when we (Snyder) revisited this village to collect a sample of clay, there was no evidence of occupation. However, a little more than 10 years later, when we (Snyder) returned to Ngatpang Village to map it (Snyder and Butler 1997), there was a family living there and beginning the construction of a house. They identified themselves as one of the grandchildren of the elderly woman interviewed by Osborne, though they had not met him because their parents were living at the time in villages in other parts of Babeldaob Island. Many cultural factors enter into our behaviour, including kinship, rights to land, politics, religion and subsistence. There is no doubt much more to these stories than we gathered from brief interviews. But time and time again, we were struck by the depth of knowledge of these so-called abandoned villages and the capability for people to shift the distribution of relatively compact villages across the Palauan landscape.

One of the themes of the Pacific Island archaeology in the 21st century conference was sustainability, exploring how Pacific peoples can sustain their livelihoods and cultures into the future. The concept of sustainability when coupled with the related concepts of resilience and flexibility is useful for our ideas on traditional Palauan settlement. Archaeological theory is too often rooted in structures such as phases or types that resist efforts to explain change. With the concept of the archaeological phase, one assumes a stasis throughout a region during a period of time. We hope that in this paper, we are successful in conveying the idea that traditional Palauan culture was dynamic. Its ability to change and adapt to changing environmental conditions and the introduction of new ideas, concepts and material culture allows traditional Palauan culture to achieve sustainability.

Our strategy in developing settlement-system models is to begin with the delineation of a pattern. A settlement pattern brings together procurement, processing, use and discard, from contemporaneous activities, integrating activities throughout the archipelago. A pattern brings together contemporaneous activities, but also extends across time because this is a cultural pattern. And, with its extent across time and space, the pattern will exhibit a range of variability. Within the pattern, we seek to analyse the relationships among many different activities. A sustainable pattern should allow for reinforcement of different activities through the range of variability. Different patterns are recognised when analysis indicates that activities are no longer integrated and no longer reinforcing. Primarily, the analysis is accomplished through comparisons. This strategy allows us to propose and analyse different perspectives before delineating a settlement system. In this regard, our strategy contrasts with other approaches that begin by delineating a classificatory system of periods and phases that further requires the delineation of a separate settlement system within each period.

The settlement pattern in Palau during the period of around AD 1300 to the present has focused on somewhat compact villages. These villages are nucleated settlements with houses and community centres clustered in a central area. In many, if not most, of the larger village areas there were several nucleated villages in close proximity. For example, in Melekeok there is 
a series of villages along the coastline. Not readily obvious to an outsider is that the villages are clearly named and delineated. In the 1980s, we observed people living in some of these villages while other villages were idle. Within this nucleated settlement pattern, the distance between villages, or clusters of villages, was much greater than the distances between houses within the cluster. Rock Island villages at Mariar, Ngeanges and the Ngemelis group mirror the nucleated pattern to the degree possible within the karstic terrain.

We also have begun to discern nucleated villages as part of the Earthwork Era between about $500 \mathrm{BC}$ and $\mathrm{AD}$ 600-800 (e.g. Liston 2009). It is the roughly 600-800-year period between about $\mathrm{AD} 600$ and $\mathrm{AD} 800$ (the end of the Earthwork villages) and $\mathrm{AD} 1300$ (the beginning of the Stonework Village Era) that we find particularly interesting. What explains this lengthy period of a seeming absence of nucleated villages in Palau? Is this due to sampling and the placement of archaeological investigations? Is this due to our inability to archaeologically recognise older components that are inter-mixed with the traditional villages that we currently understand to date to the past 400 years? Or is this because the settlement pattern in Palau was different at that time?

There are several factors that lead us to think that we should carefully consider the likelihood of a distinct dispersed settlement pattern in Palau between the Earthwork and Stonework Village eras. In the Rock Islands, Masse (Masse 1989; Masse et al. 2006) has demonstrated that midden deposits are present, lying below Stonework Village Era components, with these deposits being particularly rich and diverse in Uchularois Cave around AD 800-900, based on radiocarbon dating of charcoal. This led Masse to propose a period of smaller dispersed settlements in the Rock Islands coinciding with the large-scale abandonment of Earthwork Era villages and terraces and forest expansion in the interior of at least portions of Babeldaob (Liston 2009).

There are many different possible scenarios that could account for the current findings. It isn't our intention to be categorical about a final answer, but rather to propose a testable hypothesis. With testing of several hypotheses, we can move towards a robust interpretation. Embedded in our models are the concepts of 'nucleated' and 'dispersed', which we use to organise and describe our observations, keeping in mind that nucleated and dispersed are not mutually exclusive states. We view these as continuous - that is, we seek to measure the degree of nucleation and the degree of dispersal in the settlement pattern.

We offer as a hypothesis that the settlement pattern in Palau before $500 \mathrm{BC}$ and between AD 800 and AD 1300 was characterised by a dispersed pattern. In contrast to the nucleated pattern of villages, in the dispersed pattern individual households were surrounded by a variety of kitchen gardens. There was relatively greater emphasis on the exploitation of resources associated with terraces. Individual households were relatively evenly distributed around the margins of the islands. Individual households may have included several buildings associated with resource-processing locations. It seems likely that households were integrated into alliances, perhaps based on kinship. It is possible that the population in Palau has been roughly the same $(25,000-50,000)$ since before 500 BC. We lack sufficient data to allow even speculation on population trends. However, there is no reason to assume that population is a major driver in shifts between dispersed and nucleated settlement patterns. A dispersed settlement pattern would have resulted in equal and sustained pressure on resources in the lagoon and on the land. Masse and Carucci both found evidence of sustained pressure on lagoon resources over a span of several centuries at the end of the first millennium $\mathrm{AD}$.

Shifting settlement patterns from dispersed to nucleated, perhaps several times over a span of several millennia, would have provided Palauans a basis of sustainability. It is apparent from oral traditions that even during periods of intense nucleation, such as during the period of 
stonework villages, there were often shifts in settlement as a response to changing environmental and social conditions. In the lagoon, a dispersed settlement pattern allows exploitation to be spread out, but in general the total yield would be less than obtained by more focused patterns. On the land, a dispersed settlement pattern minimises environmental degradation, but may make intensification of exploitation of a resource and social networking more difficult than with a nucleated settlement pattern.

The terraces functioned in a number of different ways. Comparing Palauan terraces with terraces in many other places, it seems likely that in addition to their use for villages and defensive posturing, an important function would be to control and manage water flow. The terraces slowed water flow during periods of high rainfall and thus lessened erosion, and they also slowed water flow during periods of low rainfall to conserve soil moisture and extend resource availability. As the soil on the terraces wore out, emphasis would have shifted to other kinds of resources, especially resources of the lagoon. But with less management of the terraces, there would have been greater erosion. Together, the erosion and the increasing exploitation of the lagoon resources would have diminished the resources of the lagoon. Shifting to a nucleated settlement pattern with a number of idle villages would have allowed the intensive exploitation of taro swamp gardens and other resources at the now nutrient-rich zone where the land meets the mangroves, and would have allowed regeneration of both land and lagoon areas around idle villages.

It is also important to point out the likelihood that at no time were the Rock Islands considered 'uninhabitable' by ancient Palauans. Limestone islands and coral atolls are a ubiquitous feature in Micronesia and island Southeast Asia. Although such environments require a fair amount of intervention by their human occupants (Kirch 2000:181-182) to provide some of the necessities for basic sustenance (e.g. fresh water or coconut milk, suitable areas for gardens, shells for tools and containers), these are well known to western Pacific Islanders and have been for thousands of years. In addition, the Rock Islands, even when not occupied for semi-permanent or permanent habitation, such as during the stonework village period, were well known to the people in the surrounding volcanic and platform islands. Memory and oral traditions of the Rock Islands and associated reefs would have provided many choices for settlement and resource-collection options. The other thing to remember about the Rock Islands is that based on the presence of ceramics as early as the 3100-2900 BP midden deposits on Ulong, the Rock Islands were never completely isolated from the volcanic islands. In fact, one of the notable aspects of the stonework village period in the Rock Islands is the fact that sherds are a major component of all midden deposits. Hundreds of ceramic vessels were probably brought to each Rock Island village every year. There is much still to understand about trade and exchange between the Rock Islands and the volcanic and platform islands.

In summary, shifts between dispersed and nucleated settlement patterns would have allowed Palauans to maintain sustainable ecological relationships over long periods of time. It is admittedly easy to postulate a settlement pattern in the absence of data. We believe that the models of Palauan settlement systems we outline in this paper offer testable hypotheses. Archaeological testing needs to be extended to lowland sites and locations between villages and at the end of villages, with sufficient sensitivity in the archaeological testing techniques to detect traces of activity areas and residences, if any exist, that are not as clearly demarcated as activity areas around stone platforms. Archaeological testing on terraces needs to expand to expose sufficient area with sufficient sensitivity in the archaeological testing techniques to expose activity areas and additional functional information. Additional archaeological survey and testing is also needed in the Rock Islands, especially at sites not immediately associated with 
large Rock Island stonework villages. In particular, we need to provide comparative data from analysis of shell middens, from both Rock Island and volcanic island sites, to test models of lagoon-resource exploitation and models of resource exchange.

\section{Archaeology, sustainability and the future of Palau}

Too often, archaeologists forget that our research has applied as well as scientific values and results. If anything, the Pacific Island archaeology in the 21st century conference should remind us that living Pacific Islanders and not just fellow archaeologists should be the primary beneficiaries of our work. Certainly, the validation of oral traditions is one important applied finding. No traditional cultural-knowledge keeper should feel anything other than respect and gratitude from anthropologists, archaeologists and historians for the gift of their precious oral traditions. And we scientists and scholars should never forget that the gift of precious and sacred oral tradition is usually only forthcoming when we have earned the trust and at least the tacit permission to use this gift appropriately and wisely.

In a similar vein, it is now our task to rethink the sterile or often unsettling archaeological concept of settlement system in order to put it into a context that better serves modern Palauans (Figure 3). Perhaps the easiest way to describe our model of the traditional Palauan settlement system is by noting that Palauans did not put all their settlement 'eggs' in one basket. The traditional Palauan settlement system had the inbuilt flexibility to achieve a new formation when environmental and/or social conditions changed. The system was sustainable, flexible and resilient because the overall diversity and variability of resources in the Palau archipelago buffered and facilitated changes in the settlement system.

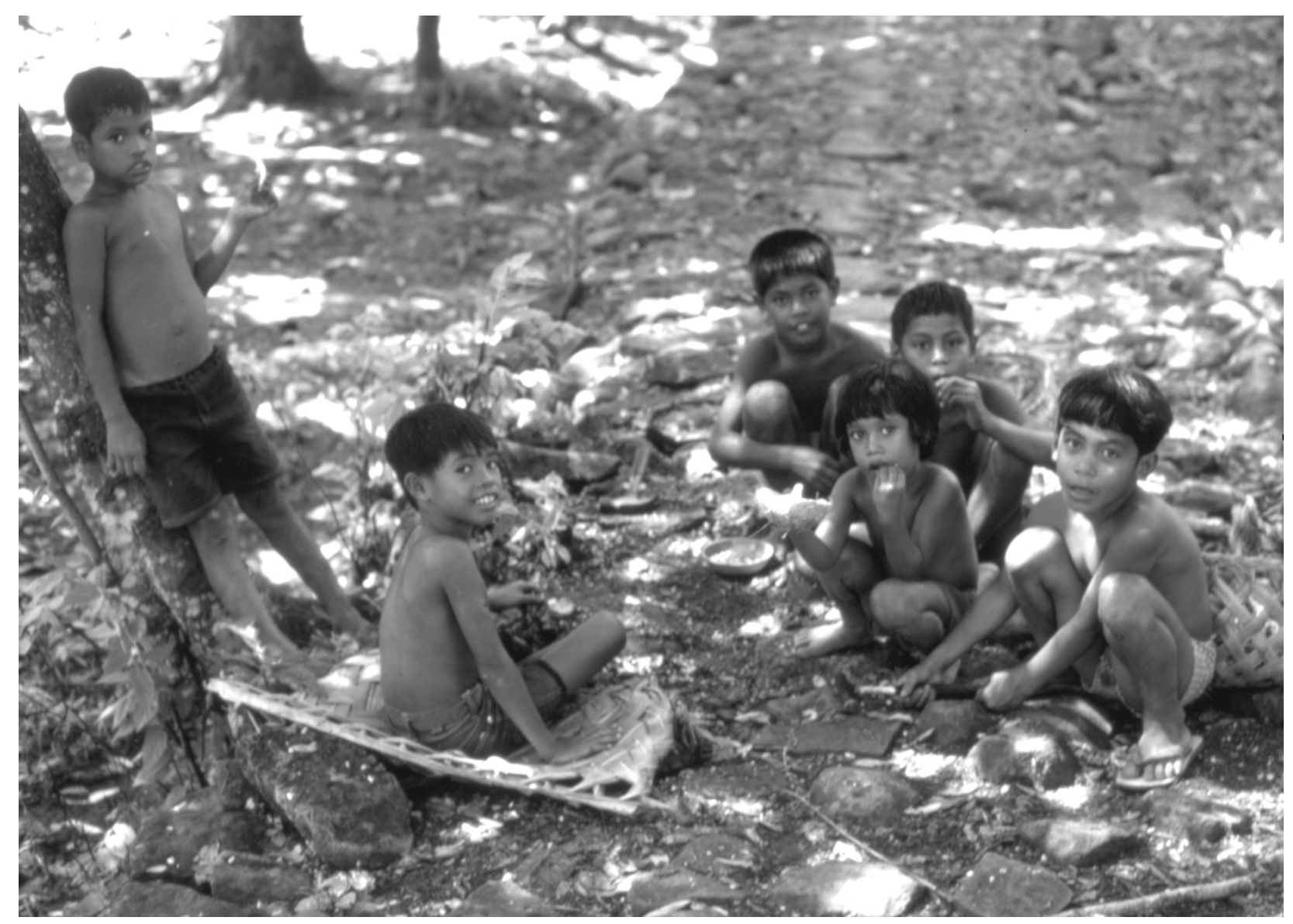

Figure 3. Palauan children on a stonework village path. 
Even with global warming and the potential of rapidly rising sea levels, there is no reason to think that contemporary and future Palauans will be any less successful with coping and adapting their settlement systems than was the case for their ancestors, described above. It is comforting to know that although people had not yet arrived in Palau at the end of the last ice age some 14,000 years ago, Palau and its incredible reefs survived a rise in sea level much more rapid and potentially catastrophic than anything that is likely to result from the present global warming (Kayanne et al. 2002).

\section{Acknowledgements}

Joni L. Manson helped much with drafting the conceptual ideas for this paper. George Gumerman and Brian Butler provided collegial encouragement and support for our Palau research. Moses Sam, Vicki Kanai, Moses Mekoll and the late Rita Olsudong provided critical assistance for our research and fieldwork from the Palau Historic Preservation Office. Vince Blaiyok and Water Metes served as crew chiefs for our 1981 surveys and test excavations, and have since served in numerous capacities to aid our work. Colleagues Jolie Liston, Geoffrey Clark, Scott Fitzpatrick and Steve Athens furnished us with copies of their recent publications. We are particularly grateful to the many Palauans, young and old, who took the time to share with us their love for and lore of Palau. The past, present and future of Palau remains as a gift and a promise for future generations. The authors of this paper are pleased and thankful to have played a small role in this evolving drama. 


\section{References}

Athens, J.S. and Ward, J.V. 2001. Paleoenvironmental evidence for early human settlement in Palau: The Ngerchau core. In: Stevenson, C.M. and Morin, F.J. (eds), Pacific 2000: Proceedings of the Fifth International Conference on Easter Island and the Pacific, pp. 165-78. Easter Island Foundation, Los Osos.

Barber, E.W. and Barber, P.T. 2004. When they severed earth from sky: How the human mind shapes myth. Princeton University Press, Princeton, NJ.

Cashman, K.V. and Giordano, G. 2008. Volcanoes and human history. Journal of Volcanology and Geothermal Research 176:325-329.

Carneiro, R.L. 1981. The chiefdom: Precursor of the state. In: Jones, G.D. and Kautz, R. (eds), The transition to statehood in the New World, pp. 37-79. Cambridge University Press, Cambridge.

Carucci, J. 1992. Cultural and natural patterning in prehistoric marine foodshell from Palau, Micronesia. Unpublished PhD thesis, Southern Illinois University, Carbondale (Ann Arbor, MI, University Microfilms International).

Clark, G. 2005. A 3000-year culture sequence from Palau, western Micronesia. Asian Perspectives 44:349-380.

Clark, G., Anderson, A. and Wright, D. 2006. Human colonisation of the Palau Islands, western Micronesia. Journal of Island and Coastal Archaeology 1:215-232.

Fitzpatrick, S.M. 2003. Early human burials in the western Pacific: Evidence for a ca. 3000 year old occupation on Palau. Antiquity 77(298):719-731.

Fitzpatrick, S.M. and Kataoka, O. 2005. Prehistoric fishing in Palau, Micronesia: Evidence from the northern Rock Islands. Archaeology in Oceania 40:1-13.

Fitzpatrick, S.M. and Donaldson, T.J. 2007. Anthropogenic impacts to coral reefs in Palau, western Micronesia during the Late Holocene. Coral Reefs 26:916-930.

Force, R.W. and Force, M. 1972. Just one house: A description and analysis of kinship in the Palau Islands. Bernice P. Bishop Museum Bulletin 235, Bishop Museum Press, Honolulu.

Gagan, M.K., Hendy, E.J., Haberle, S.G. and Hantoro, W.S. 2004. Postglacial evolution of the IndoPacific Warm Pool and El Niño-Southern Oscillation. Quaternary International 118-119:127-143.

Gumerman, G.J., Snyder, D. and Masse, W.B. 1981. An archaeological reconnaissance in the Palau Archipelago, Western Caroline Islands, Micronesia. Southern Illinois Center for Archaeological Investigations Research Paper 23, Carbondale.

Holcomb, R.T. 1987. Eruptive history and long-term behaviour of Kilauea Volcano. In: Decker, R.W., Wright, T.L. and Stauffer, P.H. (eds), Volcanism in Hawaii, Volume 1. US Geological Survey Professional Paper 1350, pp. 261-350. Washington, DC.

Intoh, M. 1986. Pigs in Micronesia: Introduction or re-introduction by the Europeans. Man and Culture in Oceania 2:1-26.

Intoh, M. 2008. Historical significance of the Southwest Islands Palau. In: Clark, G., Leach, F.L. and O'Connor, S. (eds), Islands of inquiry: Colonisation, seafaring and the archaeology of maritime landscapes, pp. 325-338. Terra Australis 29, ANU EPress.

Johannes, R. 1981. Words of the lagoon; Fishing and marine lore in the Palau district of Micronesia. University of California Press, Berkeley.

Kayanne, H., Yamono, H. and Randall, R. 2002. Holocene sea-level changes and barrier reef formation on an oceanic island. Palau Islands, western Pacific. Sedimentary Geology 150:47-60.

Keate, G. 2002. An account of the Pelew Islands. In: Nero, K.L. and Thomas, N. (eds), Leicester University Press, London.

Kirch, P.V. 2000. On the road of the winds: An archaeological history of the Pacific Islands before European contact. University of California Press, Berkeley.

Krämer, A. 1919. In: Thilenius, G. (ed), Ergebnisse der Südsee-Expedition 1908-1910. II. Ethnographie; B. Mikronesien. Band 3, Teilband 2. Friederichsen, Hamburg (Human Relations Area file typescript, anonymous translation). 
Kubary, J.S. 1873. Die Palau-Inseln in der Sudsee. Journal des Museum Godeffroy 1:181-238 (Human Relations Area File typescript, translated by Anonymous).

Liston, J. 1999. Palau Compact Road, archaeological investigations, Babeldaob Island, Republic of Palau. Phase II: Data recovery. Volume V: Laboratory analysis, synthesis, and recommendations. Draft report prepared for the U.S. Army Engineer District, Honolulu, Ft. Shafter, Hawai i i. International Archaeological Research Institute, Inc., Honolulu.

Liston, J. 2005. An assessment of radiocarbon dates from Palau, western Micronesia. Radiocarbon 47:295-354.

Liston, J. 2009. Cultural chronology of earthworks in Palau, western Micronesia. Archaeology of Oceania 44:56-73.

Liston, J. and Tuggle, H.D. 2006. Prehistoric warfare in Palau. In: Arkush, E. and Allen, M.W. (eds), The archaeology of warfare: Prehistories of raiding and conquest, pp. 148-183. University Press of Florida, Gainesville.

Lucking, L. 1984. An archaeological investigation of prehistoric Palauan terraces. Unpublished PhD thesis, Department of Anthropology, University of Minnesota.

Lucking, L J. and Parmentier, R.J. 1990. Terraces and traditions of Uluang: Ethnographic and archaeological perspectives on a prehistoric Belauan site. In: Hunter-Anderson, R. (ed), Recent advances in Micronesian archaeology. Micronesica Supplement 2:125-136.

Mason, A.C. 1955. Geology of the limestone Islands, Palau, Western Caroline Islands. Unpublished PhD thesis, Department of Geology, University of Illinois. University Microfilms, Ann Arbor.

Masse, W.B. 1981. Field notes on file at the Center for Archaeological Investigations, Southern Illinois University, Carbondale.

Masse, W.B. 1985. Review of 'Words of the Lagoon: Fishing and marine lore in the Palau District of Micronesia' by Johannes, R.E. (1981 - University of California Press, Berkeley). Copeia 1985:797-798.

Masse, W.B. 1986. A millennium of fishing in the Palau Islands, Micronesia. In: Anderson, A. (ed), Traditional fishing in the Pacific: Ethnographic and archaeological papers from the $15^{\text {th }}$ Pacific Science Congress. Pacific Anthropological Records 37, pp. 85-117. Bernice Pauahi Bishop Museum, Honolulu.

Masse, W.B. 1989. The archaeology and ecology of fishing in the Belau Islands, Micronesia. Unpublished $\mathrm{PhD}$ thesis, Southern Illinois University, Carbondale (Ann Arbor, MI, University Microfilms International).

Masse, W.B. 1990. Radiocarbon dating, sea-level change, and the peopling of Belau. In: HunterAnderson, R. (ed), Recent advances in Micronesian archaeology. Micronesica Supplement 2:213230.

Masse, W.B. 1991. The quest for subsistence sufficiency and civilization in the Sonoran Desert. In: Crown, P.L. and Judge, W.J. (eds), Chaco and Hohokam: Prehistoric regional systems in the American Southwest, pp. 195-223. School of American Research Press, Santa Fe.

Masse, W.B. 1995. The celestial basis of civilization. Vistas in Astronomy 39:463-477.

Masse, W.B. 2010. The celestial engine at the heart of traditional Hawaiian culture. Paper prepared for 'Astronomy and power: How worlds are structured', the European Society for Astronomy and Culture 18th Annual Meeting, Gilching, Germany, August 30-September 4, 2010.

Masse, W.B., Carter, L.A. and Somers, G.M. 1991. Waha'ula heiau, the regional and symbolic context of Hawai i Island's "Red Mouth" temple. Asian Perspectives 30:19-56.

Masse, W.B. and Snyder, D. 1982. The final report of the 1981 field season of the Southern Illinois University Palau Archaeological Project. Report prepared for Historic Preservation Office, US Trust Territory of the Pacific Islands, Saipan. Center for Archaeological Investigations, Southern Illinois University, Carbondale.

Masse, W.B., Snyder, D. and Gumerman, G.J. 1984. Prehistoric and historic settlement in the Palau Islands, Micronesia. New Zealand Journal of Archaeology 6:107-127. 
Masse, W.B., Liston, J., Carucci, J. and Athens, J.S. 2006. Evaluating the effects of climate change on environment, resource depletion, and culture in the Palau Islands between AD 1200 and 160. Quaternary International 151:106-132.

Masse, W.B., Barber, E.W., Piccardi, L. and Barber, P.T. 2007. Exploring the nature of myth and its role in science. In: Piccardi, L. and Masse, W.B. (eds), Myth and geology. Geological Society of London Special Publication 273.

McPherson, D.L., Blaiyok, V.K. and Masse, W.B. 2010. Unusual predatory and aggressive behaviors of Black-tip reef sharks (Carcharhinus melanopterus) and Jacks (Carangidae) in the Palau Islands, Micronesia. Submitted to Environmental Biology of Fishes.

Masse, W.B., Johnson, R.K. and Tuggle, H.D. n.d. Islands in the sky: Traditional astronomy and the role of celestial phenomena in Hawaiian myth, language, religion, and chiefly power. University of Hawai $\mathrm{i}$ Press, Honolulu [Manuscript in preparation].

Nero, K.L. 1987. A Cherechar a Lokelii: Beads of history of Koror, Palau, 1783-1983. Unpublished PhD thesis, University of California, Berkeley (Ann Arbor, MI, University Microfilms International).

Nero, K.L. 2002. In: Nero, K.L. and Thomas, N. (eds), An Account of the Pelew Islands-George Keate, pp. 1-25. Leicester University Press, London.

Nunn, P.D. 2000. Environmental catastrophe in the Pacific Islands around A.D. 1300. Geoarchaeology 15(7):715-740.

Nunn. P.D. 2007. Climate, environment, and society in the Pacific during the last millennium. Elsevier Science, New York.

Ogg, J.G. and Koslow, J.A. 1978. The impact of typhoon Pamela (1976) on Guam's coral reef communities. Environmental Biology of Fishes 3:49-63.

Osborne, D. 1958. The Palau Islands: Stepping stones into the Pacific. Archaeology 11:162-171.

Osborne, D. 1966. The archaeology of the Palau Islands, an intensive survey. BP Bishop Museum Bulletin 230, Bishop Museum Press, Honolulu.

Osborne, D. 1979. Archaeological test excavations, Palau Islands, 1968-1969. Micronesia Supplement 1.

Parmentier, R.J. 1981. The sacred remains: An historical ethnography of Ngeremlengui, Palau. Unpublished PhD thesis, University of Chicago (Ann Arbor, MI: University Microfilms International).

Parmentier, R.J. 1987. The sacred remains: Myth, history, and polity in Belau. University of Chicago Press, Chicago.

Phear, S. 2008. Subsistence and inland landscape transformations: Investigating monumental earthworks in Ngaraard State, Republic of Palau, Micronesia: A landscape perspective. In: Clark, G., Leach, F.L. and O'Connor, S. (eds), Islands of inquiry: Colonisation, seafaring and the archaeology of maritime landscapes, pp. 301-324. Terra Australis 29, ANU EPress.

Piccardi, L. and Masse, W.B. (eds), 2007. Myth and geology. Geological Society of London Special Publication 273.

Reff, D. 1991. Disease, depopulation, and culture change in Northwestern New Spain, 1518-1754. University of Utah Press, Salt Lake City.

Rubin, D.C. 1995. Memory in oral traditions. Oxford University Press, Oxford.

Semper, K. 1982. The Palau Islands in the Pacific Ocean (Translated by M Berg). Micronesian Area Research Center, University of Guam (Original German edition, 1873).

Service, E.R. 1962. Primitive social organization. Random House, New York.

Snyder, D. 1989. Towards chronometric models for Palauan prehistory: Ceramic attributes. Unpublished PhD thesis, Southern Illinois University, Carbondale (Ann Arbor, MI, University Microfilms International).

Snyder, D. and Butler, B.M. 1997. Palau archaeology: Archaeology and historic preservation in Palau. Micronesian Resources Study, Anthropology, Research Series 2. Micronesian Endowment for Historic Preservation Republic of Palau. U.S. National Park Service, San Francisco.

Stannard, D. 1989. Before the horror: The population of Hawaii on the eve of Western contact. University of Hawai i Press, Honolulu. 
Swanson, D.A. 2008. Hawaiian oral tradition describes 400 years of volcanic activity at Kilauea Volcano. Journal of Volcanism and Geothermal Research 176:427-431.

Takayama, J. 1979. Archaeological investigation of PAAT-2 in the Palaus: an interim report. In: Kusakabe, F. (ed), Cultural anthropological research on the folk culture in the Western Caroline Islands of Micronesia in 1977, pp. 81-103. Tokyo University of Foreign Studies, Tokyo.

Takayama, J. and Takasugi, H. 1978. Preliminary report of the archaeological excavation of PAAT-2, in Palau. Overseas Scientific Research, Ministry of Education, Japan. Tokyo University of Foreign Studies, Tokyo. Manuscript on file, Historic Preservation Office, Republic of Palau, Koror.

U.S. Army, 1956. Military geology of Palau Islands, Caroline Islands. U.S. Geological Survey, Washington, D.C.

Vansina, J. 1985. Oral tradition as history. University of Wisconsin Press, Madison.

Vessel, A.J. and Simonson, R.W. 1958. Soils and agriculture of the Palau Islands. Pacific Science 12:281-298.

Wickler, S. 2002. Oral traditions and archaeology: Modeling village settlement in Palau, Micronesia. Micronesian: Journal of the Humanities and Social Sciences 1:39-47.

Wickler, S.K., Welch, D.J., Tomonari-Tuggle, M.J., Liston, J., Tuggle, H.D. and Grant, D.M. 2005. Palau Compact Road archaeological investigations, Babeldaob Island, Republic of Palau. Phase I: Intensive archaeological survey. Volume I: Scope, background, results, evaluation, and recommendations. Prepared for U.S. Army Corps of Engineers, Pacific Ocean Division, Ft. Shafter, Hawai i. IARII, Honolulu, Hawai'i (Report ID 566).

Yamaguchi, M. 1975. Sea level fluctuations and mass mortalities of reef animals in Guam, Mariana Islands. Micronesica 11:227-243. 